\title{
Research Paper: Women and Methamphetamine in Iran: A Report From the Most Populous Persian Gulf Country
}

\author{
Afsaneh Moradi ${ }^{1}$ (D), Omid Massah ${ }^{2 *}$ (D)
}

1. Department of Psychology, Persian Gulf University, Bushehr, Iran.

2. Substance Abuse and Dependence Research Center, University of Social Welfare and Rehabilitation Sciences, Tehran, Iran.

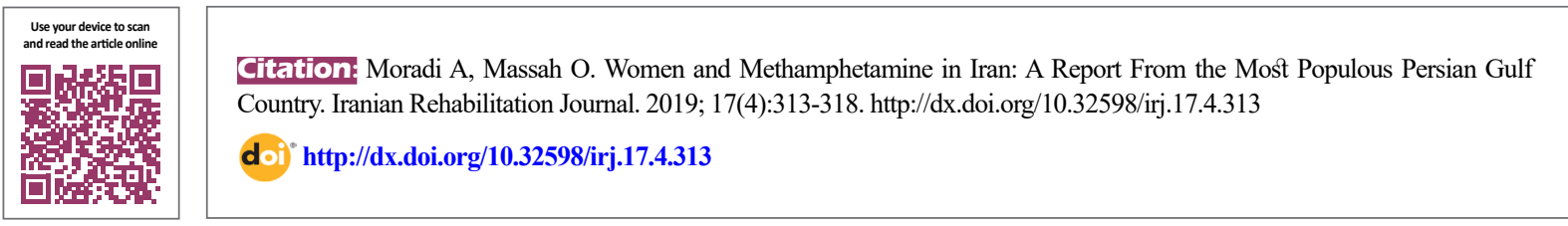

\section{(i) (5)}

Article info:

Received: 23 Jun 2019

Accepted: 27 Oct 2019

Available Online: 01 Dec 2019

\section{Keywords:}

Drug, Harm reduction, Women, Methamphetamine, Iran

\section{A B S T RACT}

Objectives: Methamphetamine (MA) use disorder is a new health problem among Iranian female methadone patients that needs special treatment and rehabilitation services. However, few describe their baseline characteristics, their reasons for MA use while in treatment, and their treatment needs and success. The study aimed at investigating these research gaps.

Methods: The participants were 70 women with MA use disorder in two large women-only methadone treatment services in Tehran, Iran. A researcher-made checklist, the Severity of Dependence Scale, the Contemplation Ladder, and the General Health Questionnaire-28 were completed by women in a baseline interview.

Results: The Mean \pm SD age of the participants was $35.84 \pm 8.62$ years. The participants reported high severity of MA dependence (Mean $\pm \mathrm{SD}=6.88 \pm 3.19$ ), poor motivation to change (Mean $\pm \mathrm{SD}=4.0 \pm 2.31]$ ), and impaired psychological well-being (Mean $\pm \mathrm{SD}=16.35 \pm 4.04$ ) in the treatment. The most important reasons for MA use while undergoing methadone treatment included self-treatment (55\%) and pleasure-seeking (43\%). The most important MA treatment needs included effective psychological treatments (75\%), continued family support (72\%), and life skills $(68 \%)$. Stable living and financial conditions $(90 \%)$, drug-free living and working places $(86 \%)$, continued family support $(78 \%)$, and psychological counseling $(69 \%)$ were the most important reported factors associated with MA treatment success.

Discussion: The current study indicated that participants reported a number of MA-related problems. This issue needed a comprehensive treatment program at individual, social, psychological, and professional levels. The findings have important implications for delivering psychosocial treatments, as well as gender-specific research.

\footnotetext{
* Corresponding Author:

Omid Massah, MD.

Address: Substance Abuse and Dependence Research Center, University of Social Welfare and Rehabilitation Sciences, Tehran, Iran. Tel: +98 (21) 71732830
}

E-mail: omchomch@gmail.com 


\section{Highlights}

- The high severity of MA dependence, poor motivation to change, and impaired psychological well-being were common. Reasons for MA use while undergoing methadone treatment included self-treatment and pleasure-seeking. MA treatment needs included effective psychological treatments, continued family support, and life skills.

- Stable living and financial conditions, drug-free living and working places, continued family support, and psychological counseling were the factors associated with MA treatment success.

\section{Plain Language Summary}

The research reports the baseline characteristics of female methadone patients with MA use disorder. Self-treatment and pleasure-seeking were the reasons for MA use. Effective psychological treatments continued family support, and life skills were needed to treat women. Stable living and financial conditions, drug-free living and working places, continued family support, and psychological counseling were needed for MA treatment success.

\section{Introduction}

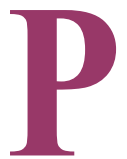

ersian women constitute $10 \%$ of the illicit drug users in Iran, but few published studies are available about this population [1]. Although women in Iran use opiates such as opium as traditional drugs, in recent years, Methamphetamine (MA) use disorder has become a common drug problem [2]. This issue remains a serious health concern, especially among women while undergoing methadone treatment because of the negative impacts of MA use disorder on positive treatment outcomes [3]. The increased MA availability and its stimulant effects are the reasons for the prevalence of its regular use among female methadone patients. The other reason is primarily related to self-treatment because of depression and or internal and external stressors such as financial problems [1-3].

The characteristics of male and female MA patients have been found different [4]. Female MA patients are less likely than men to be employed and married $[5,6]$; they also report greater severity of MA dependence than their male counterparts [4-7] and report more clinically relevant psychological problems such as depression and anxiety [7]. However, women appear to respond better to MA treatment than do men [6-8]. Furthermore, women are more likely than men to remain in MA treatment [8] because they have a lot of motivation to succeed in treatment [9].

To date, few studies have been conducted on Iranian MA patients. Recent studies indicate that the high prevalence of MA use disorder remains a health problem among Iranian female methadone patients [10]. MA first appeared in 2005, when illegally imported from Southeast Asia, and recently, MA has been largely manufactured in the Persian context [1]. A study was conducted on female methadone patients in Tehran and reported that all participants are dependent on MA. MA served as a self-treatment for depression in treatment [11].

MA treatment is based on psychosocial interventions such as cognitive-behavioral therapy and the Matrix Model (a 16-week outpatient psychosocial treatment) [11-14]. However, there is no widely available psychosocial treatment for MA patients in the Persian context [12-14]. To date, there are few studies of Iranian women and MA use disorder while undergoing methadone treatment. The current research is among the first studies reporting the baseline characteristics of a group of female methadone patients with MA use disorder, their reasons for MA use while undergoing treatment, their treatment needs, and their reasons for treatment success.

\section{Methods}

\section{Study sites}

The study sites included two large women-only methadone treatment services (Khaneh Khorshid and NavidHamrazi-Iranian) in Tehran, Iran. The first study site was located in the Shush area and the second study site was located in the Molavi area.

\section{Participants}

Female MA patients were individually approached and invited by the site managers to attend an information session about the study. All of them were referred to a psy- 
chologist for a screening interview to determine eligibility. The inclusion criteria included being a woman, being 18 years and older, having any route of MA administration while undergoing methadone treatment, having the psychiatric diagnosis of MA use disorder while undergoing methadone treatment based on Diagnostic and Statistical Manual of Mental Disorders, $5^{\text {th }}$ Edition, being in methadone treatment process for at least 3 months, and being enthusiastic and able to comply with the study requirements [15]. The exclusion criteria included selfreported severe medical and or psychiatric problems, as well as drug withdrawal and or intoxication symptoms at the time of enrolment. Overall, 90 female patients were interviewed for 6 months in 2015. Of them, 20 were excluded because of the lack of meeting all the inclusion criteria. Overall, 70 eligible women were included and referred to trained research staff to complete the questionnaires.

\section{Measures}

A demographic questionnaire was designed and piloted on 30 women before conducting the study. The test-retest assessment was $86 \%$, which indicated high reliability. A part of the checklist included open-ended questions that were related to the reasons for MA use in treatment, MA treatment needs, and reasons for success in MA treatment. The design of the questionnaire was based on the baseline section of the Opiate Treatment Index [16]. The Persian version of the Severity of Dependence Scale (SDS) is a standardized measure for assessing the severity of MA dependence. The SDS is a 5-item questionnaire and the scores range between 0 and 15 while the cut-off of at least 4 indicates MA dependence [17]. The Persian version of the Contemplation Ladder is a standardized measure for assessing motivation to change. The scores range between 0 and 10 . While a score of 0 indicates no readiness to change and a score of 10 indicates high readiness to change [18]. The Persian validated the version of the General Health Questionnaire (GHQ-28) is a standardized measure for assessing psychological wellbeing and the scores range between 0 and 28 [19]. Higher scores on the GHQ-28 indicate more problems [19].

\section{Ethical considerations}

All participants signed the consent form and were informed that their identities would be confidential and anonymous. The study was part of a research, which was approved by Tehran University of Medical Sciences.

\section{Statistical analysis}

All data were analyzed, using mean, percent, and frequency. The SPSS software version 22 was used to analyze the data.

\section{Results}

\section{Demographic characteristics}

The mean age of the participants was (Mean $\pm \mathrm{SD}=$ $35.84 \pm 8.62)$ years. Half of the participants reported living with their families $(50 \%)$. However, some participants reported homelessness and the lack of stable living conditions at the time of intake (14\%). Most of the participants were divorced $(45 \%)$. Most of the participants were unemployed (52\%) and reported elementary schooling (49\%). Lifetime MA treatment was reported by some participants $(30 \%)$, which was limited to the therapeutic community (Table 1).

\section{Drug and treatment characteristics}

The participants reported a high severity of MA dependence (Mean $\pm \mathrm{SD}=6.88 \pm 3.19$ ) on the SDS, poor motivation to change (Mean $\pm \mathrm{SD}=4.0 \pm 2.31)$ on the Contemplation Ladder, and impaired psychological well-being (Mean \pm SD $=16.35 \pm 4.04$ ) on the GHQ-28 in treatment (Table 2).

\section{Reasons for MA use, treatment needs, and success}

The most important self-reported reasons for MA use while undergoing methadone treatment included selftreatment $(n=39,55 \%)$ and pleasure-seeking $(n=30$, $43 \%$ ). The most important self-reported MA treatment needs included effective psychological treatments $(n=53,75 \%)$, continued family support $(n=51,72 \%)$, and life skills $(\mathrm{n}=48,68 \%)$. Stable living and financial conditions ( $\mathrm{n}=63,90 \%$ ), drug-free living and working places $(n=60,86 \%)$, continued family support $(n=55$, $78 \%)$, and psychological counseling $(n=48,69 \%)$ were the most important self-reported factors associated with MA treatment success.

\section{Discussion}

The results of the study indicated that most participants were young, divorced, and unemployed and lived with their families. Furthermore, they reported a low-level of education. Although the participants were in the methadone treatment process for months, they reported MA use disorder. A study indicated that most Iranian female 
Table 1. Demographic characteristics $(n=70)$

\begin{tabular}{|c|c|c|}
\hline \multicolumn{2}{|c|}{ Characteristics } & \multirow{2}{*}{$\frac{\text { Mean } \pm S D \text { or No. (\%) }}{35.84 \pm 8.62}$} \\
\hline Age, $y$ & Age range: $20-60$ y & \\
\hline \multirow{3}{*}{ Living conditions } & With family & $35(50)$ \\
\hline & Without family & $25(36)$ \\
\hline & Homeless/ unstable & 10(14) \\
\hline \multirow{4}{*}{ Marriage } & Divorced & $32(45)$ \\
\hline & Married & $27(37)$ \\
\hline & cinglo & $7(10)$ \\
\hline & Semanted & $(8)$ \\
\hline \multirow{5}{*}{ Employment } & Jobless & $36(52)$ \\
\hline & Housewife & $25(36)$ \\
\hline & & \\
\hline & Student & $5(7)$ \\
\hline & Employed & $4(5)$ \\
\hline \multirow{5}{*}{ Education } & Elementary & $34(49)$ \\
\hline & High school & $27(39)$ \\
\hline & & \\
\hline & $12-16 y$ & $9(12)$ \\
\hline & Lifetime MA treatment & $21(30)$ \\
\hline
\end{tabular}

methadone patients are divorced and unemployed and reported a low level of formal education [20].

Participants reported poor psychological well-being, which was likely to negatively impact their methadone treatment outcomes. A study of MA female patients indicated that women report poor psychological well-being while undergoing treatment [21]. Poor psychological well-being is likely to lead to depression and anxiety, which are associated with self-treatment with MA use among women. Effective interventions need to be delivered to reduce poor psychological well-being and increase positive methadone treatment outcomes.

Participants reported poor motivation to change and received no substantial MA treatment. A study indicated

Table 2. MA use characteristics

\begin{tabular}{cc}
\hline Characteristics & Mean \pm SD \\
\hline Age of the first use of MA (y); age range: $17-46$ y & $29.73 \pm 11.05$ \\
\hline Duration of MA dependence, range: $1-8 \mathrm{y}$ & $5.35 \pm 1.87$ \\
\hline Severity of MA dependence, score range: $5-9$ & $6.88 \pm 3.19$ \\
\hline Psychological well-being, score range: $8-23$ & $16.35 \pm 4.04$ \\
Motivation to change & $4.0 \pm 2.31$ \\
\hline Duration of methadone treatment y & $2.50 \pm 1.70$ \\
\hline
\end{tabular}


that motivational interviewing is a beneficial strategy to encourage treatment entry and retention among women with MA use disorder [10]. Motivational interviewing needs to be provided for these women to increase motivation to change as part of continued MA treatment while undergoing methadone treatment. Since the Matrix Model remains long and unaffordable for a large proportion of methadone patients, the implementation of short-term and affordable psychosocial interventions should be considered within the context of methadone treatment $[14,22]$.

The high severity of MA dependence while undergoing methadone treatment was considered in this study. This issue is important because an untreated MA dependence is very likely to lead to poor methadone treatment outcomes. This is consistent with a study that indicated that female methadone patients reported high severity of MA addiction while undergoing treatment [2]. Because of the potentially harmful effect of MA dependence on methadone treatment outcomes, treatment is an essential need for these women.

Women in this study reported a number of reasons for MA use, their treatment needs, and their reasons for potential treatment success. As illicit drug use is a health problem among methadone patients, which needs treatment, effective treatment interventions should partly consider these reasons [23, 24]. Further studies are suggested to investigate these reasons among large groups of female methadone patients.

The current study not only makes a contribution to MA research literature but also extends and develops knowledge and understanding of a relatively under-researched group of women in West Asia. However, the study was limited to female MA patients in the methadone treatment process. Therefore, the findings may not be generalizable to other groups of MA patients in the community or men in methadone treatment services. Additional studies are suggested in the Persian context.

\section{Conclusion}

These findings not only highlight the need for the consideration of gender when assessing MA use disorder but also can serve to direct efforts at delivering effective psychosocial treatments. Simultaneously, the delivered psychosocial treatments need to improve the social and health contexts of the patients such as psychological well-being and motivation to change. This issue needs to be accompanied by treating medical and psychiatric comorbidities related to long years of continued drug use.
MA treatment needs to be integrated within the overall opiate treatment for Persian female methadone patients.

\section{Ethical Considerations}

\section{Compliance with ethical guidelines}

All of the ethical considerations have been considered in this research. All research steps and methods were in compliance with the 1975 Declaration of Helsinki. Before entering the study, the subjects studied the written consent form and then signed it. No identifying information was documented.

\section{Funding}

This research did not receive any specific grant from funding agencies in the public, commercial, or not-forprofit sectors.

\section{Authors' contributions}

Conceptualization, formal analysis, methodology, software: Afsaneh Moradi; Investigation, writing-original draft, supervision, project administration: Afsaneh Moradi and Omid Massah; Writing-review and editing: Omid Massah.

\section{Conflict of interest}

The authors declare no conflicts of interest.

\section{References}

[1] Rafiey H, Ghaderi S, Morovat B, Noori R, Effatpanah M, Mahjoub A, et al. Amphetamine type stimulants use in the adult population of Tehran: Implication for long term rehabilitation. Iranian Rehabilitation Journal. 2017; 15(4):303-8. [DOI:10.29252/nrip.irj.15.4.303]

[2] Dana S, Effatpanah M, Mahjoub A. The new epidemic problem of psychoactive drugs at drug treatment centers of Iran: Implications for education, prevention and treatment. Iranian Journal of Psychiatry and Behavioral Sciences. 2018; 12(2):e63555. [DOI:10.5812/ijpbs.63555]

[3] Tavakoli M, Effatpanah M, Moradi A, Mahjoub A. Methamphetamine dependence among Iranian female methadone patients: A cross-sectional survey of three cities of Iran. Iranian Journal of Psychiatry and Behavioral Sciences. 2018; 12(2): e62866. [DOI:10.5812/ijpbs.62866]

[4] Simpson JL, Grant KM, Daly PM, Kelley SG, Carlo G, Bevins RA. Psychological burden and gender differences in methamphetamine-dependent individuals in treatment. Journal of 
Psychoactive Drugs. 2016; 48(4): 261-9. [DOI:10.1080/0279107 2.2016.1213470] [PMID]

[5] Han Y, Lin V, Wu F, Hser Y-I. Gender comparisons among Asian American and Pacific Islander patients in drug dependency treatment. Substance Use \& Misuse. 2016; 51(6): 752-62. [DOI:10.3109/10826084.2016.1155604] [PMID] [PMCID]

[6] Rungnirundorn T, Verachai V, Gelernter J, Malison RT, Kalayasiri R. Sex differences in methamphetamine use and dependence in a Thai treatment center. Journal of Addiction Medicine. 2017; 1(1): 19-27. [DOI:10.1097/ ADM.0000000000000262] [PMID] [PMCID]

[7] Zweben JE, Cohen JB, Christian D, Galloway GP, Salinardi M, Parent D, et al. Psychiatric symptoms in methamphetamine users. American Journal of Addiction. 2004; 13(2): 18190. [DOI:10.1080/10550490490436055] [PMID]

[8] Dluzen DE, Liu B. Gender differences in methamphetamine use and responses: A review. Gender Medicine. 2008; 5(1): 24 35. [DOI:10.1016/S1550-8579(08)80005-8]

[9] Esmaili A, Shishehgar S, Massah O. Methadone Maintenance Treatment in Iran and Brief Psychological Treatments for Women: A Rehabilitation Approach in Methamphetamine Dependence. Archives of Rehabilitation. 2019; 20(3):2229. [DOI:10.32598/rj.20.3.222]

[10] Salimi S, Effatpanah M, Mahjoub A. Motivational interviewing can facilitate entry to matrix treatment for methamphetamine dependence. Iranian Journal of Psychiatry and Behavioral Sciences. 2018; 12(2). e63560. [DOI:10.5812/ ijpbs.63560]

[11] Shakiba K, Effatpanah M, Moradi A. Cognitive-behavioral therapy for methamphetamine dependence among methadone-maintained patients. Iranian Journal of Psychiatry and Behavioral Sciences. 2018; 12(2): e63615. [DOI:10.5812/ ijpbs.63615]

[12] Shariatirad S, Mahjoub A, Haqiqi A, Rezaei Hemami M, Tofighi B, Ekhtiari H, et al. Buprenorphine added on brief cognitive behavioral therapy for treatment of methamphetamine use disorder. Iranian Journal of Psychiatry and Behavioral Sciences. 2018; 12(2): e11529. [DOI:10.5812/ijpbs.11529]

[13] Massah O, Effatpanah M, Shishehgar S. Matrix model for methamphetamine dependence among Iranian female methadone patients: The first report from the most populated Persian Gulf country. Iranian Rehabilitation Journal. 2017; 15(3): 193-8. [DOI:10.29252/nrip.irj.15.3.193]

[14] Sami S, Effatpanah M, Moradi A, Massah O. Matrix model as an intensive rehabilitation in three methadone services in Iran. Iranian Rehabilitation Journal. 2017; 15(3): 293-7. [DOI:10.29252/nrip.irj.15.3.293]

[15] American Psychiatric Association. Diagnostic and Statistical Manual of Mental Disorders, 5th Edition: DSM-5. USA Washington; 2013. [DOI:10.1176/appi.books.9780890425596]

[16] Darke S, Hall W, Wodak A, Heather N, Ward J. Development and validation of a multi-dimensional instrument for assessing outcome of treatment among opiate users: The Opiate Treatment Index. British Journal of Addiction. 1992; 87(5): 733-42. [DOI:10.1111/j.1360-0443.1992.tb02719.x] [PMID]

[17] Gossop M, Darke S, Griffiths P, Hando J, Powis B, Hall W, et al. The Severity of Dependence Scale (SDS): Psychometric properties of the SDS in English and Australian samples of heroin, cocaine and amphetamine users. Addiction. 1995; 90 (5): 607-14. [DOI:10.1046/j.1360-0443.1995.9056072.x] [PMID]

[18] Biener L, Abrams DB. The Contemplation Ladder: Validation of a measure of readiness to consider smoking cessation. Health Psychology. 1991; 10 (5): 360-5. [DOI:10.1037//02786133.10.5.360] [PMID]

[19] Khosravi A, Mousavi SA, Chaman R, Sepidar Kish M, Ashrafi E, Khalili M, et al. Reliability and validity of the Persian version of the World Health Organization-five well-being index. International Journal of Health Studies. 2015; 1(1): 17-9.

[20] Alam Mehrjerdi Z, Abarashi Z, Mansoori S, Deylamizadeh A, Salehi-Fadardi J, Noroozi A, et al. Methamphetamine use among Iranian heroin Kerack-dependent women: Implications for treatment. International Journal of High Risk Behaviors and Addiction. 2013; 2(1): 15-21. [DOI:10.5812/ ijhrba.10216] [PMID] [PMCID]

[21] Roshanfekr P, Noori R, Dejman M, Fathi Geshnigani Z, Rafiey H. Drug use and sex work among at-risk women: A qualitative study of initial factors. Iranian Journal of Psychiatry and Behavioral Sciences. 2015; 9(2): e953. [DOI:10.17795/ ijpbs953] [PMID] [PMCID]

[22] Effatpanah M, Moradi A. Methamphetamine dependence and technology-based interventions in Iran. Iranian Journal of Psychiatry and Behavioral Sciences. 2018; 12(2): e62935. [DOI:10.5812/ijpbs.62935]

[23] Massah O, Effatpanah M, Moradi A, Salehi M, Farhoudian A, Karami Z. Barriers to hepatitis $C$ treatment among women in methadone treatment: A study from Iran, the most populous Persian Gulf country. Addiction Health. 2017; 9(4):229 36. [PMID]

[24] Khoramizadeh M, Effatpanah M, Mostaghimi A, Rezaei M, Mahjoub A, Shishehgar S. Treatment of amphetamine abuse/ use disorder: A systematic review of a recent health concern. Daru J Pharm Sci. 2019; 27, 743-753. [DOI:10.1007/s40199-019-00282-3] [PMID] 